\title{
Libros Nuevos
}

\section{INVESTIGACIÓN CUALITATIVA: MIRADAS DESDE EL TRABAJO SOCIAL ${ }^{1}$}

\author{
Nilsa M. Burgos Ortiz
}

Los debates sobre la investigación en trabajo social giran principalmente en torno a los múltiples enfoques y perspectivas teóricas-metodológicas, en los procesos de llevar a cabo la misma y en los métodos de su enseñanza. El hecho de trabajar con poblaciones diversas nos permite entender y hacer visibles a personas que probablemente son ignoradas en la sociedad. Se presenta la investigación cualitativa como una abierta al empleo de diferentes métodos, interesada en la vida cotidiana, una que valora perspectivas de las personas participantes, en la que la persona que investiga es el principal instrumento y una que requiere creatividad, pensamiento reflexivo y crítico.

Este libro consta de ocho capítulos, además de esta sección de introducción, la de referencias bibliográficas y apéndices. Los capítulos son ilustrados con ejemplos de investigaciones en América latina y Puerto Rico, referencias bibliográficas y contenido en cursos de investigación. Los mismos han sido desarrollados desde el trabajo social, no para competir con otras disciplinas, sino para demostrar la posible colaboración. En el texto se utiliza lenguaje inclusivo, partiendo que la profesión de trabajo social es una mayoritariamente ejercida por mujeres y para reconocer sus aportaciones en igualdad a los hombres.

El primer capítulo se refiere a la caracterización de la investigación cualitativa partiendo de un breve trasfondo histórico. El segundo capítulo gira en torno a la base teórica, exponiendo sobre perspectivas teóricas muy utilizadas en las investigaciones cualitativas y otras alternas. En el tercer capítulo se inicia el proceso de investigación tomando en consideración los aspectos éticos que deben regir cualquier investigación para

${ }^{1}$ Espacio Editorial, Buenos Aires, Argentina, 2011. ISBN 978-950-802-

${ }^{2}$ Catedrática Escuela Graduada de Trabajo Social Beatriz Lassalle, Universidad de Puerto Rico en Río Piedras 
proteger a las personas participantes. Se incluye el problematema, la pertinencia del estudio, el contexto conceptual y personal asumiendo la realidad como múltiple y la diversidad de perspectivas.

El cuarto capítulo se dedica a las personas participantes, su selección y la relación con investigadores e investigadoras. Para el quinto capítulo, se identificaron los diseños que aparecen con mayor frecuencia en la literatura como son: el estudio de caso, etnografía, historia oral, la investigación acción participativa, la observación partícipe y la evaluación cualitativa. Se incluye también, dos estrategias de investigación en torno a la política social.

En relación a las técnicas de recopilación de datos, que constituye el sexto capítulo, se presentan las siguientes: entrevista semi-estructurada, historia de vida y testimonio, grupo focal, observación, diario de campo, documentos, fotografía y video grabación. El séptimo capítulo comprende el análisis e interpretación de información, comenzando con la transcripción, en los casos de grabaciones. El análisis abarca la elaboración de categorías y sub-categorias. El énfasis de la interpretación es alrededor del significado de la información, el cual tiene un enfoque holístico considerándose el contexto cultural, la particularidad de la situación o experiencia, las vinculaciones entre categorías y posicionar algunos de los datos cuando sea pertinente en marco conceptual y literatura. Se incluye el análisis de discurso como una herramienta de análisis con una investigación realizada en Chile sobre las políticas sociales con enfoque familiar. EI capítulo finaliza con el narrativo y la comunicación de resultados de la investigación. El octavo y último capítulo gira en torno a la evaluación de la investigación cualitativa incluyendo estrategias para incrementar el rigor, criterios de calidad y la triangulación.

Este libro demuestra que nuestra profesión ha producido y continuará produciendo conocimiento desde diversas investigaciones cualitativas que nos han servido a nuestro quehacer profesional al igual que ha sido una contribución para otras disciplinas. El hecho de trabajar con poblaciones diversas aunque sean en mayoría gente pobre, nos permite entender y visibilizar a personas que probablemente son ignoradas por la academia. 